\title{
A REPRODUÇÃO DAS RELAÇÕES DE PRODUÇÃO E A EDUCAÇÃO ESCOLAR
} CAPITALISTA

\author{
LA REPRODUCCIÓN DE LAS RELACIONES DE PRODUCCIÓN Y LA EDUCACIÓN \\ ESCOLAR CAPITALISTA
}

\section{THE REPRODUCTION OF THE RELATIONS OF PRODUCTION AND CAPITALIST SCHOOL EDUCATION}

\author{
DOI: https://doi.org/10.9771/gmed.v13i3.44390
}

\author{
Paulo Henrique de Vasconcelos ${ }^{1}$
}

Maria Cristina dos Santos ${ }^{2}$

\begin{abstract}
Resumo: As discussões sobre o papel da escola como instrumento de reprodução da sociedade capitalista emergem com vigor na década de 1960, são alastradas pela área da educação ao longo dos anos e, então, retomadas pela chamada nova sociologia da educação e impregnadas pelo pós-estruturalismo e posteriormente pelo pósmodernismo. O objetivo deste texto é dar vida nova à categoria da reprodução e sua relação com a educação escolar, situando-a (novamente) no âmbito do materialismo dialético. Foi realizada uma análise conceitual ancorada principalmente nos pressupostos legados por Henri Lefebvre e pela pedagogia histórico-crítica. No momento histórico atual a reprodução toma à frente e culmina em um processo de desumanização programada no interior da escola, marcada pela promoção de um desenvolvimento psicológico intencionalmente deficiente.
\end{abstract}

Palavras-chave: Vida cotidiana. espaço social. pedagogia histórico-crítica.

Resumen: Las discusiones sobre el papel de la escuela como instrumento de reproducción de la sociedad capitalista surgieron vigorosamente en la década de 1960, se extendieron por el campo de la educación a lo largo de los años y luego fueron retomadas por la llamada nueva sociología de la educación, impregnadas por el posestructuralismo y más tarde por el posmodernismo. El objetivo de este texto es dar nueva vida a la categoría de la reproducción y su relación con la educación escolar, colocándola (nuevamente) en el ámbito del materialismo dialéctico. Se realizó un análisis basado en los fundamentos dejados por Henri Lefebvre y por la pedagogía histórico-critica. En el momento histórico actual, la reproducción toma la delantera y culmina en un proceso de deshumanización en la escuela, marcado por un desarrollo psicológico intencionalmente deficiente.

Palabras clave: Vida cotidiana. Espacio social. Pedagogía histórico-crítica.

Abstract: Discussions about the role of the school as an instrument for the reproduction of capitalist society emerged vigorously in the 1960s, being spread throughout the area of education over the years and then resumed by the so-called new sociology of education and impregnated by post-structuralism and later by post-modernism. This text aims to give new life to the category of reproduction and its relations with school education, situating it (again) within the scope of dialectical materialism. A conceptual analysis was carried out based mainly on the assumptions left by Henri Lefebvre and the historical-critical pedagogy. In the current historical moment, reproduction takes the lead and culminates in a programmed dehumanization process within the school, marked by the promotion of an intentionally deficient psychological development.

Keywords: Everyday life. social space.historical-critical pedagogy. 


\section{Introdução}

On the horizon, then, at the furthest edge of the possible, it is a matter of producing the space of the human species - the collective (generic) work of the species - on the model of what used to be called 'art'; [...]

The creation (or production) of a planet-wide space as the social foundation of a transformed everyday life open to myriad possibilities - such is the dawn now beginning to break on the far horizon (LEFEBVRE, 1991, p. 422) ${ }^{3}$

Toda e qualquer teoria pedagógica sempre encerra, positiva ou negativamente, um posicionamento quanto ao indivíduo que espera formar, bem como uma aproximação ou um afastamento em relação à concepção de indivíduo predominante em determinada formação social, defendida e disseminada, via de regra, pelo poder estatal, quase que como um modelo de cidadão almejado que é disseminado, principalmente, pela escola pública. Consideramos que uma teoria pedagógica que nega a existência de uma intencionalidade formativa pode ser entendida basicamente de duas maneiras: possui uma certa inocência ao se ver alijada da necessidade de estipular objetivos claros para o ser humano que pretende formar, o que resulta na sua aderência às intencionalidades formativas dominantes; ou deliberadamente dissimula suas intencionalidades formativas, seja pela necessidade de obscurecer pressupostos sociais de reprodutibilidade do gênero humano para a manutenção do modo de produção dominante, ou por uma patente incapacidade de planejamento e de discussão teórica que conceba uma perspectiva minimamente totalizante de ser humano. Por isso, não podemos prescindir de firmar nosso posicionamento, de estabelecermos a intencionalidade para a formação humana que possuímos ao redigir este trabalho.

Nossa argumentação funda-se em uma perspectiva materialista dialética, que por sua vez compreende que a escola é uma instituição cuja função é a transmissão do conhecimento sistematizado principalmente os conhecimentos científico, filosófico e artístico - e elaborado ao longo da história da humanidade, tendo como objetivo último uma formação humana que possibilite aos indivíduos o domínio teórico e prático destes conhecimentos para a realização de uma práxis revolucionária, que não apenas analise e critique a realidade, mas que também atue direta e programaticamente em sua transformação. Ao nos posicionarmos desta maneira, nos juntamos àqueles que combatem toda e qualquer perspectiva educacional reformista ou apologética inerente ao modo de produção dominante, qual seja, o modo de produção capitalista, como também suas principais características e intencionalidades em relação à função social da escola, que visa principalmente a reprodução de suas relações de produção.

Dito isto, o ser humano que pretendemos formar é aquele que viverá, ou ao menos se esforçará e atuará conscientemente para construir uma outra sociedade, em um espaço social que diverge radicalmente deste que atualmente vivemos. Um sujeito que concebe a existência humana e a realidade enquanto experiência que, independente de suas marcas positivas ou negativas na vida cotidiana, deve ser apropriada, interiorizada e constantemente transformada, não de maneira cega ou impulsiva mas planejada, utilizando como fundamento a objetivação dos conhecimentos a ele legados culturalmente e por ele apropriados. Definiremos provisoriamente esta expectativa formativa como homem total, aquele 
que se apropria omnilateralmente da realidade em que vive, como nos é elucidado por Marx (2010, p. 108, grifos no original):

\begin{abstract}
O homem se apropria da sua essência omnilateral de uma maneira omnilateral, portanto como um homem total. Cada uma das suas relações humanas com o mundo, ver, ouvir, cheirar, degustar, sentir, pensar, intuir, perceber, querer, ser ativo, amar, enfim todos os órgãos da sua individualidade, assim como os órgãos que são imediatamente em sua forma como órgãos comunitários, [...] são no seu comportamento objetivo ou no seu comportamento para com o objeto a apropriação do mesmo, a apropriação da efetividade humana; seu comportamento para com o objeto é o acionamento da efetividade humana (por isso ela é precisamente tão multíplice [...] quanto multíplices são as determinações essenciais e atividades humanas), eficiência humana e sofrimento humano, pois o sofrimento, humanamente apreendido, é uma autofruição do ser humano.
\end{abstract}

A citação de Marx, acima transcrita, é interessante por pontuar de maneira bastante clara o que o autor concebe como homem total, inclusive situando-o no escopo de suas relações imediatas da vida, na relação individualizada do ser humano com a realidade em que vive. Esta perspectiva destoa de apropriações pedagógicas do materialismo dialético para a defesa de uma "educação para o trabalho" ou de uma "educação para a leitura do mundo". No primeiro caso, ao falarmos de uma educação para o trabalho, de uma educação fundamentada na atividade humana voltada para um fim, deliberadamente intencional, que transforma tanto a realidade com a qual o indivíduo entra em contato como o próprio indivíduo, podemos concordar apenas parcialmente. Este tipo de assertiva fez-se válida em períodos históricos localizados, como por exemplo na Revolução Russa de 1917, onde urgia a necessidade de uma rápida industrialização do país, tendo em vista a fuga da população da fome, da miséria e da alienação tecnológica que se alastrava no território russo ${ }^{4}$. Mas a educação para o trabalho não pode ser considerada como um pressuposto educativo geral, aplicável a todos os contextos, pois o ser humano, se considerado como um homem total, não pode ser simplesmente reduzido ao trabalho. Ao utilizarmos a categoria do trabalho para uma compreensão totalizante do ser humano, devemos sempre historicizá-la: foi com o surgimento do trabalho que o ser humano pôde se diferenciar dos outros seres vivos ao longo de sua história biológica; foi por meio do trabalho que o ser humano alcançou o desenvolvimento tecnológico e social que hoje podemos vislumbrar; é por meio do trabalho que o ser humano é explorado pelo modo de produção capitalista na atualidade, mais especificamente, pela expropriação do mais-trabalho. Quanto a este terceiro ponto, devemos acrescentar que o trabalho não é o único meio de exploração do trabalhador, embora seja o determinante. Não defenderemos aqui uma educação para o trabalho que se limita à libertação de apenas um dos aspectos que constituem o ser humano, arriscando cair em uma perspectiva unilateral da humanidade, nos afastando da formação omnilateral preconizada pelo próprio Marx. Defendemos uma educação para a formação humana total, ou, dito de outro modo, adequando o conceito de Marx aos tempos e necessidade atuais, uma formação do humano total.

Já quanto às perspectivas pedagógicas que adotam o materialismo dialético em defesa da formação de indivíduos aptos a lerem a realidade em que vivem 5 , será necessário argumentarmos, primeiramente, sobre a linguagem. A linguagem não pode ser considerada, de maneira alguma, como um simples meio de comunicação, como mera ferramenta tornada disponível para que o pensamento de um 
indivíduo seja expresso, compreendido e assimilado pelo pensamento de outrem (LEFEBVRE, 2014b). Por outro lado, a linguagem também não pode ser considerada como a expressão máxima do legado histórico, social e cultural da humanidade, como se ela fosse uma entidade definidora daquilo que podemos compreender como humano. Esta última assertiva redundaria em uma fragmentação do humano total, pois a linguagem é apenas um dos níveis que constituem o ser humano, um signo. Subsumir o indivíduo à linguagem, denominando-o sujeito da linguagem - ou, até mesmo, um de seus desdobramentos nas teorias pedagógicas atuais, um sujeito da cultura, ou o que de fato deveriam assumir: o sujeito enquanto partícula individualizada em um número incontável de grupos culturais - seria o equivalente a esquartejar suas dimensões constituintes, culminando na defesa de uma perspectiva reducionista e não totalizadora do gênero humano. A defesa por processos educativos que atuam para a formação de um indivíduo apto a ler a realidade em que vive é um desdobramento deste mesmo pensamento reducionista, mesmo que julgando atuar diretamente em uma formação humana crítica - o que infelizmente se tornou apenas mais um dos clichês pedagógicos, e não mais um posicionamento radical no interior das intencionalidades formativas - que minimiza todos os produtos e criações da atividade humana em função da linguagem: a prática social, a cultura, a política, as relações sociais, as relações de poder, a própria realidade em que vivemos, as instituições nas quais estamos inseridos; todas estas instâncias da vida humana são consideradas textos a serem interpretados pelo aluno em formação, ou pelo sujeito da linguagem ou, ainda, pelo sujeito cultural que vive e lê do seu próprio modo o texto que se coloca à sua frente.

O que vigora nestas perspectivas, para além da defesa do fragmentário, é o apreço pela manutenção de um espaço social abstrato que, como tentaremos demonstrar adiante, é uma das características do modo de produção capitalista. Este posicionamento se torna, mesmo que contra a sua vontade, ao menos a que superficialmente expressa, um desdobramento ideológico de apologia ao modo de produção capitalista, que por sua vez encontra conforto nesta modalidade da formação humana, com a certeza de que a palavra “[...] never saved the world and it never will” (LEFEBVRE, 1991, p. 134)6.

O que podemos esperar de uma teoria pedagógica fundamentada no materialismo dialético, de característica omnilateral e que almeja a formação humana total, é a intencionalidade de que as dimensões constitutivas do ser humano não sejam fragmentadas, de que sejam levadas em consideração a cultura, a linguagem, o trabalho - tratados como elementos centrais, respectivamente, nas perspectivas pedagógicas freireanas, pós-modernas e voltadas para o trabalho -, todo o conjunto de experiências que constituem a vida cotidiana de cada um de nós e que, na sociedade atual, são podadas ou expropriadas uma a uma, com maior ou menor intensidade. Não nos referimos aqui apenas aos aspectos positivos da vida humana, pois até os negativos, como o sofrimento humano, possuem sua manifestação cingida, seja por via médica, dopando os sentidos do corpo humano e o impedindo de experienciar a vida em sua totalidade, seja pelos momentos de lazer oferecidos pelo entretenimento de massas, que fazem com que o indivíduo seja lançado, de seu sofá, até um mundo de maravilhas, distanciando-o da realidade concreta, aproximando-o de uma realidade que nunca será alcançada se não abstratamente (LEFEBVRE, 2014a). 
Compreendemos o equívoco que reside na defesa de uma compreensão essencialista de ser humano, que o enredaria em definições fixas que são por fim inseridas como objetivos no interior das instituições da sociedade, preconizando a formação de indivíduos formais, sujeitos a uma determinada estrutura social, mas sem qualquer conteúdo que não aqueles já preconizados a nível estatal e econômico. Isso não quer dizer que a complexidade de uma definição objetiva e total para o ser humano deva nos manter afastados da intencionalidade de definir, de conceitualizar e de categorizar a vida humana, de comprendê-la em uma perspectiva totalizante, pois sem um fundamento teórico que abranja, ao menos, aquilo que conseguimos enxergar em um horizonte de possibilidades para a vida humana no tempo histórico atual, cairíamos em um relativismo do qual não poderíamos mais ser resgatados, do qual não conseguiríamos nos mexer, nele residiríamos inertes, pois para nos mexer é preciso, no mínimo, ter clareza de onde queremos chegar.

Feitas as devidas considerações e após oferecermos ao leitor uma maior clareza da formação humana - preconizada por uma perspectiva materialista dialética da educação - que aqui defendemos, podemos afirmar que a única teoria pedagógica que se aproxima do materialismo dialético e desta formação humana total, ao menos no Brasil, é inegavelmente a pedagogia histórico-crítica. Esta, por sua vez, emerge a partir de esforços individuais de Dermeval Saviani que, no final da década de 1970, assumiu um caráter coletivo na busca por uma teoria pedagógica que superasse as formulações das teorias por ele denominadas de crítico-reprodutivistas (SAVIANI, 2011b). Era esperada a elaboração de uma teoria pedagógica que não mais considerasse a escola apenas como palco de reprodução da sociedade capitalista, reforçando seu caráter dialético e contraditório como um dos importantes ambientes de formação para propiciar a transformação futura da sociedade.

Desde seu momento de formação até os dias atuais, diversos autores têm colaborado para a constituição da pedagogia histórico-crítica, tomando como fundamento diversas áreas do conhecimento, esforçando-se para uma formulação pedagógica cada vez mais afinada com os preceitos do materialismo dialético. Dentre estes esforços, emerge uma grande influência da psicologia histórico-cultural, representada principalmente pela Escola de Vigotski, que direciona as discussões dos principais autores comprometidos com o enriquecimento da pedagogia histórico-crítica. É fecunda e necessária a articulação entre uma teoria pedagógica e uma teoria psicológica do desenvolvimento humano pois sua relação, obviamente, propiciou diversos avanços, possibilitando compreendermos como se dá o funcionamento psicológico daqueles indivíduos que aprendem, qual é a importância e a especificidade da educação escolar na apropriação destes conhecimentos, do ponto de vista do desenvolvimento psicológico, e como os processos de apropriação e interiorização dos conhecimentos elaborados contribuem para o desenvolvimento das funções psicológicas superiores, do pensamento, do domínio da linguagem, da formação do pensamento em conceitos, etc.

Ao mesmo tempo em que a pedagogia histórico-crítica se esforçou, e ainda se esforça, para alcançar níveis cada vez mais rebuscados de fundamentação teórica, principalmente via fundamentação das teorias psicológicas, houve um recrudescimento quanto à discussão sobre qual seria o conhecimento que se torna objeto da formação humana, ao menos em seus aspectos filosóficos e sociológicos. Germinal: Marxismo e Educação em Debate, Salvador, v. 13, n. 3, p. 238-258, dez. 2021. ISSN: 2175-5604 242 
Houveram poucos desenvolvimentos sólidos sobre esta questão, sendo normalmente endereçada à pergunta sobre "qual conhecimento deve permear a educação escolar na perspectiva da pedagogia histórico-crítica" a resposta de que seriam os conteúdos clássicos, ricos em determinações, que resistiram ao embate do tempo histórico e se mostraram verdadeiros quando confrontados com a realidade (SAVIANI, 2011b).

Os conteúdos buscados pela pedagogia histórico-crítica para a inserção na educação escolar não são aqueles, como preconizados pelas pedagogias tradicionais, dotados de certa pureza epistemológica, mas sim aqueles dotados de viabilidade crítica: são almejados os conhecimentos criticamente produzidos e criticamente aplicáveis, o resto não nos interessaria, seriam apenas discursos (LEFEBVRE, 2014a) conceitualmente esvaziados.

A sociedade capitalista promove também, em relação à maior parte da população, o estranhamento dos conhecimentos elaborados e sistematizados ao longo da história da humanidade, tornando-os uma propriedade privada, garantindo o seu domínio apenas para um pequeno grupo, o dominante. Estas formulações remetem à própria concepção de produção do conhecimento defendida pelo materialismo dialético, presente já em Marx (2011), com a diferença de que os conteúdos clássicos constituem um recorte da totalidade dos conhecimentos elaborados ao longo da história da humanidade para aplicação no ambiente escolar. A própria consideração de que o conhecimento é produzido coletivamente pelo conjunto dos homens, que foi apropriado privadamente pelo capital e transformado em força produtiva para a autovalorização do capital (MARX, 1978) é também proveniente do arcabouço teórico do materialismo dialético.

Não há problema algum em herdar estas discussões daqueles pensadores que instigaram a formulação do materialismo dialético, contudo, respostas prontas e direcionamentos pré-formulados poderiam apenas satisfazer em um primeiro momento aqueles interessados pelo desenvolvimento da pedagogia histórico-crítica. Considerando o devir desta teoria pedagógica, não mais podemos nos conformar e nos limitar a tais saídas. Como poderíamos, com tais respostas de cunho simplista, formuladas de maneira quase que automática, responder questões que nos são direcionadas, questões de grande complexidade, tais como: de que modo a sociedade capitalista afasta da maior parte da população o conhecimento elaborado e sistematizado? É uma atividade ativamente planejada ou mera consequência de suas características fundantes? Se é planejada, quais os mecanismos utilizados para tal? Seria de fato um afastamento ou a promoção de uma apropriação aligeirada e fragmentada? Quais são os pressupostos ideológicos e quais são as teorias pedagógicas que fomentam a reprodução das relações de produção capitalistas no interior das instituições escolares? Se estas mesmas ideologias e teorias pedagógicas não sustentam de maneira deliberada a reprodução da sociedade capitalista, como é que elas dissimulam tais preceitos? De que modo o conhecimento na educação escolar contribui, de fato, para a transformação da sociedade? Qual seria a instância social em que os conhecimentos apropriados na escola poderiam ser objetivados rumo à transformação da sociedade? Qual é a possibilidade revolucionária que a apropriação dos conhecimentos elaborados e sistematizados ao longo da história da humanidade encerra? 
Não pretendemos, no espaço destinado a este trabalho, responder a todas estas perguntas minuciosamente, pois este seria mais um esforço natimorto, aligeirado e fragmentário, e não há a necessidade da proliferação (ainda maior) de iniciativas deste tipo no ambiente acadêmico. O que faremos é o endereçamento de algumas considerações que podem nos auxiliar, em trabalhos futuros e coletivos, a responder a estas perguntas, a defender uma formação humana total e a propiciar processos de ensino e de aprendizagem que fomentem, no futuro dos indivíduos, a possibilidade de transformação da realidade em que vivem.

\section{Afirmação da desumanização: o espaço abstrato e sua estratégia educativa}

De ouro e de prata é o vosso Deus agora; / quem de vós, que o idolatra, é mais genuíno, / se vós um cento, e ele um só adora? (ALIGHIERI, 2019a, p. 137, 112-114)

Antes de qualquer aproximação elucidativa das intencionalidades formativas do modo de produção capitalista para a educação escolar, julgamos salutar iniciarmos afirmando uma das questões apontadas anteriormente: a sociedade capitalista atua direta e intencionalmente para a promoção de uma formação humana fragmentária, que afasta os indivíduos de qualquer tipo de análise crítica e radical da realidade. Isso faz com que a população se encontre constantemente imersa em uma consciência privada, imersa no individualismo, distanciada o máximo possível da compreensão da realidade em que vive e, por vezes, até mesmo instigando a produção de uma realidade abstrata, onde o indivíduo poderá repousar tranquilamente, evitando quaisquer embates e enfrentamentos de problemáticas externas. Ao utilizarmos genericamente as palavras "sociedade capitalista", fazemos referência, mais diretamente, aos representes do capital, sejam eles os capitais personificados, as instituições estatais da sociedade capitalista ou até mesmo os braços ideológicos do capital, que abraçam amorosa e reciprocamente aqueles que gozam da relatividade e da fragmentação da análise do real. A formação humana fragmentária, longe de ser passiva ou meramente consequência de outras características mais pujantes do modo de produção capitalista, é intencionalmente promovida para que a reprodução biológica e social das relações de produção seja mantida.

Não podemos considerar, de maneira alguma, que o Estado se isenta da tomada de decisões que privilegiam a reprodução da sociedade capitalista. Segundo Mészáros (2011), a reprodução das relações de produção capitalistas, denominada pelo autor de sociometabolismo, é garantida por uma série de mediações de segunda ordem que se posicionam entre os seres humanos e a reprodução das sociedades. As mediações primárias, as que ocorrem entre a humanidade e as suas condições de reprodução, são transhistóricas, ou seja, são perenes enquanto a própria humanidade existir. Contudo, em cada período histórico há mediações de segunda ordem, modificações das mediações primárias, tornadas relações entre os seres humanos e as condições de reprodução da sociedade circunscritas a um período histórico e a um modo de produção específico. Na sociedade capitalista atual, são mediações de segunda ordem a família nuclear, os meios de produção, as personificações do capital, o dinheiro e seu fetichismo, a produção 
capitalista fetichizada, o trabalho estranhado, as diversas formas de estruturação dos estados nacionais e o mercado mundial.

Há uma significativa contradição no interior da sociedade capitalista: por um lado, ocorre uma intensificação na formação dos estados nacionais para privilegiar o seu próprio desenvolvimento econômico, por outro lado, o capitalismo enquanto modo hegemônico de produção não consegue se sustentar por si próprio no interior de apenas uma única nação, pois deve constantemente ser ampliado, sua produção engloba cada vez mais porções do espaço global, sujeitando-os aos seus preceitos (MÉSZÁROS, 2011). Assim, os representantes políticos do capital, enquanto se esforçam para privilegiar as personificações locais do capital, devem ao mesmo tempo ceder às pressões externas do mercado mundial, atuando ativamente no balanço entre ambas as pretensões: a nacionalização e a globalização. Deste modo, a intervenção do Estado na esfera econômica varia de tempos em tempos, dependendo da quantidade de auxílio que as personificações do capital necessitam, dependendo do estado atual de crises em que a sociedade capitalista apresenta em um determinado tempo histórico.

Simultaneamente a estas tensões, no interior das nações, é preciso que a expropriação do maistrabalho seja assegurada, é preciso que os trabalhadores atuem na reprodução do próprio modo de produção que os agrilhoará. Neste último processo, entram em cena velhos conhecidos das teorias marxistas: o dinheiro, os meios de produção e a produção capitalista no geral. Os meios de produção se tornam propriedades das personificações do capital, que fomentam a divisão do trabalho ao máximo, dificultando qualquer possibilidade de que os trabalhadores consigam, de relance, conceber o papel que possuem na totalidade da produção capitalista. Com isso, afasta-os do reconhecimento de sua atuação enquanto transformadores ativos dos produtos com os quais trabalham, ao ponto de que a única relação que o trabalhador consegue estabelecer entre seu ofício enquanto empregado e sua atividade especificamente humana - o trabalho - reside no dinheiro que "ganha" ao final do mês, em forma de salário, como se este fosse o fim último do processo, a resposta ansiada pela necessidade humana, obscurecendo a expropriação de mais-trabalho para a autovalorização do capital que por trás dele se esconde. Nos resta, portanto, a família nuclear, de cunho hierárquico, sintonizada com a sociedade capitalista e atuando diretamente na reprodução biológica da massa de trabalhadores e na inculcação dos valores e das normas da sociedade capitalista desde a mais tenra idade, garantindo que geração após geração ocorra a reposição da massa de trabalhadores aptos e minimamente saudáveis para que possam ser plenamente explorados.

As mediações de segunda ordem atuam conjuntamente para garantir a reprodução das relações de produção capitalistas, formando estruturas que secretam e protegem o espaço social na qual se materializam, que foi produzido de acordo com as necessidades do modo de produção dominante. Caso alguma destas estruturas seja afetada, caso a família nuclear seja ameaçada pelo desenvolvimento cultural ou caso a cadeia produtiva seja afetada por uma crise econômica, como exemplos, as demais estruturas asseguram que esta modificação não comprometa a sociedade capitalista total, atuando diretamente na amenização destes problemas, seja por via reformista, adequando a estrutura afetada e as demais às novas demandas, ou plenamente reacionária, fomentando a reversão das ameaças. 
Um determinado modo de produção deve, obrigatoriamente, produzir um espaço social, formado por estruturas - sejam elas materiais ou imateriais - que garantam a sua reprodução e que seja plenamente adequadas às suas necessidades sociometabólicas; o próprio espaço social, por sua vez, retroage fomentando a reprodução de uma sociedade, alocando lugares de convívio, de trabalho, de passagem para indivíduos que deverão exercer uma prática social determinada e condicionada pelo modo de produção.

Qualquer intencionalidade de transformação da sociedade deve dirigir seus ataques não somente a uma destas estruturas, mas a todas, conjuntamente, desestabilizando o modo de produção capitalista e erradicando a sua possibilidade de flexibilização e de readequação. É preciso pensarmos onde a atividade transformadora poderá atuar, em qual instância da vida social é possível agir para que a transformação da sociedade torne-se de fato realizável e não uma mera abstração, em qual instância da vida social há a confluência de todas as estruturas que compõem as mediações de segunda ordem da sociedade capitalista. Denominamos de vida cotidiana esta conjunção das dimensões da vida social e do local de inserção e materialização das estruturas responsáveis pelo sociometabolismo.

Reconhecemos a vida cotidiana como a unidade entre três elementos: o trabalho, a vida familiar e o lazer (LEFEBVRE, 2014a). Cada um destes três elementos se relaciona com o outro, e é na interrelação entre eles que a vida cotidiana deve ser compreendida. O trabalho não se encontra isolado da vida familiar ou do lazer, da mesma forma que o lazer não se encontra desvinculado da vida familiar, etc. Todas as atividades humanas, mesmo aquelas que consideramos mais complexas - como a elucubração filosófica ou a construção inovadora de um aparato tecnológico -, possuem como início, como solo fértil, a vida cotidiana, pois é dela que as atividades, sejam elas simples ou complexas, únicas ou repetitivas, alienadas ou desalienantes, têm início (LEFEBVRE, 2014c). Da mesma maneira, é na vida cotidiana que a reprodução das relações de produção é materializada; é na vida familiar que a reprodução biológica da humanidade é garantida; é na vida familiar que a reprodução de valores e normas características de uma dada sociedade começam a ser transmitidos; é para a vida familiar que o indivíduo volta após o tempo dispendido no trabalho; é nas formas de lazer, em sua maioria alienantes e dependentes da exploração de outros trabalhadores, que o trabalhador encontra o conforto fugaz de uma vida produtiva angustiante e massacrante; este lazer pode ser próximo ou distante da vida familiar, e quando próximo pode ser individualizado ou não; é com o trabalho que o indivíduo produz, onde contempla um dos aspectos de sua humanidade, mesmo que de forma alienada, e é no trabalho que ele obtém o salário necessário para a reprodução biológica de sua família ou de si, como também obtém o salário necessário para o dispêndio em atividades de lazer.

Se partimos de uma perspectiva materialista dialética, que necessariamente implica na defesa da transformação da sociedade estabelecida fundamentada em um modo de produção capitalista, e se identificamos na vida cotidiana a confluência da atuação das estruturas de manutenção e de reprodução das relações de produção capitalistas, devemos considerar que é também na vida cotidiana que devemos depositar os nossos esforços para a suprassunção dessa sociedade. Isso não quer dizer, de maneira alguma, 
que estejamos sendo vitimados pela tentação relativista ou culturalista que vigora atualmente, que ignora as dimensões totalizantes da vida social; o que pensamos é o oposto.

A vida cotidiana não abrange apenas os aspectos particulares, individualizados e imediatos da sociedade, ela atua como uma mediação entre o particular e o universal (LEFEBVRE, 2014c), fazendo incidir na vida privada os condicionantes e determinantes da vida pública e da vida social. A transformação da vida cotidiana envolve, desta maneira, não apenas a transformação da vida individual, mas também a transformação da sociedade em que este indivíduo vive. É por isso que o processo revolucionário que visa a transformação da realidade não pode incidir apenas em sua dimensão econômica, ou então em sua dimensão produtiva, é preciso que afete todas as dimensões da vida social, é preciso que seja uma revolução total (LEFEBVRE, 2014c), pois, caso não seja, seu caráter revolucionário é extinto e ficaríamos apenas com seus vestígios, com um conjunto de mudanças reformistas e conformistas da realidade. A vida cotidiana não é mero conceito abstrato para que possamos nos apropriar de fenômenos específicos da vida social, ela é, na verdade, uma categoria concreta. Ela atinge a sua concreticidade ao tomar parte no espaço social capitalista, relacionando-se com as mediações de segunda ordem e emergindo em diferentes formas, de acordo com a prática social dos envolvidos.

Qualquer relação entre os seres humanos ou entre o ser humano e uma coisa, implica necessariamente em uma relação com o espaço social (LEFEBVRE, 1991). O espaço social capitalista, por sua vez, é considerado por Lefebvre (1991) como um espaço abstrato, tendo como principais características a busca pelo esmaecimento das diferenças - dito de outro modo, a busca pela homogeneidade social - que são forçadas a emergir apenas em suas formas simbólicas, como por meio das artes, preferencialmente abstratas; é um espaço permeado pela violência e pela burocracia, que utilizase destas em larga escala para atingir os seus objetivos. Lefebvre (1991) o define tanto por seus aspectos negativos, pela supressão das esferas históricas e políticas da sociedade, colocando sobre elas um véu de opacidade, como por seus aspectos positivos, a saber, o desenvolvimento tecnológico, as ciências aplicadas, as instâncias de produção do conhecimento fortemente atadas às relações de poder e de classe. A produção deste espaço está diretamente relacionada ao modo de produção dominante e às mediações de segunda ordem:

Capitalism and neocapitalism have produced abstract space, which includes the 'world of commodities', its 'logic' and its worldwide strategies, as well as the power of money and that of the political state. This space is founded on the vast network of banks, business centres and major productive entities, as also on motorways, airports and information lattices (LEFEBVRE, 1991, p. 53)7.

O espaço abstrato pode também ser caracterizado pela radicalização das transformações da natureza em prol do desenvolvimento tecnológico e econômico. Devemos lembrar que o trabalho, usualmente concebido apenas em seu aspecto positivo, enquanto atividade que transforma e resulta em um produto que supre as necessidades sociais, possui também um aspecto flagrantemente negativo: se a natureza é transformada por meio do trabalho, parte desta natureza é também destruída no processo; se há um alavancamento de atividades que visam diretamente a transformação da natureza, há consequentemente uma maior porção de destruição dos ambientes naturais, até o ponto em que nos 
encontramos atualmente, em que os espaços naturais tendem à inexistência (LEFEBVRE, 1991) - o que é também confirmado pela própria necessidade de reprodução ampliada do modo de produção capitalista, que necessita englobar parcelas cada vez maiores, e antes inatingíveis, do espaço global.

Neste sentido, há uma acentuação da divisão do trabalho entre as atividades produtivas materiais e abstratas, sendo que estas últimas são as consideradas mais valorosas (LEFEBVRE, 1991) ao permitirem a elaboração de estratégias para a produção e reprodução do espaço abstrato, por meio da manipulação quantitativa da estática, da programação de computadores e de projeções (LEFEBVRE, 1991) para um futuro econômico de dominação e de exploração. O espaço abstrato, portanto, supervaloriza a racionalidade lógica formal - ao menos para parcelas dos usuários deste espaço, para os quais tais conhecimentos serão transmitidos - pois é ela que permite a manipulação social e a expansão do poderio capitalista.

A racionalidade lógica formal, por sua vez, é transmitida em sua maior parte via signos, mais especificamente via linguagem em sua forma racionalizada, principalmente por meio da linguagem escrita, do Logos, dotado de gigantesca abstração. O espaço abstrato está diretamente vinculado com e depende da transmissão da linguagem abstrata via reprodução social, para que seja possível não apenas produzir e reproduzir a si mesmo, mas também as condições necessárias para tal reprodução, e é na escola onde ele irá atuar para a manutenção de suas necessidades neste quesito.

Emerge daí a supervalorização das teorias pedagógicas atuais ao considerarem o indivíduo enquanto sujeito da linguagem, em considerarem que o objetivo da educação é a leitura do mundo. Emerge também daí o motivo pelo qual consideramos, e já afirmamos, que tais teorias pedagógicas - e também as demais teorias que nelas exercem influência e de onde derivam tais pressupostos -, apesar de se colocarem, ao menos superficialmente, contra o poderio do modo de produção capitalista, na verdade atuam conjuntamente com ele, propiciando no interior das escolas, as principais instituições para a transmissão do conhecimento, o estabelecimento de instâncias sociais que visam a reprodução das relações de produção capitalistas, além de instigarem uma formação humana fragmentária, focada em apenas uma de suas dimensões constituintes, a linguagem. As propostas pedagógicas pós-modernas e multiculturalistas bebem desta mesma fonte e compartilham da mesma poluição, contudo, acentuam ainda mais o problema: para além do foco exacerbado na linguagem, desprezam e relativizam a racionalidade e a objetividade, prezando ainda mais pela subjetividade e, consequentemente, promovendo uma fragmentação ainda maior do humano total.

A vida cotidiana está imersa no espaço abstrato e compartilha de suas mesmas características, sendo por elas influenciada e também agindo para a produção e reprodução deste espaço e de seus determinantes. Por isso nossa insistência de que é na vida cotidiana que a transformação social deve de fato incidir, pois

So long as everyday life remains in thrall to abstract space, with its very concrete constraints; so long as the only improvements to occur are technical improvements of detail (for example, the frequency and speed of transportation, or relatively better amenities); so long, in short, as the only connection between work spaces, leisure spaces and living spaces is supplied by the agencies of political power and by their mechanisms 
of control - so long must the project of 'changing-life' remain no more than a political rallying-cry to be taken up or abandoned according to the mood of the moment (LEFEBVRE, 1991, pp. 59-60) ${ }^{8}$.

Mas para qual direção deveríamos proceder para a transformação da vida cotidiana e, mais adiante, do espaço abstrato? A resposta, para Lefebvre (1991), é rumarmos em direção à produção ou, mais especificamente, à criação de um espaço diferencial, onde as diferenças sociais não seriam suprimidas mas sim mantidas e alimentadas, onde a divisão do trabalho não incidiria radicalmente sobre a população, onde haveria a possibilidade de uma formação humana total, onde a vida cotidiana poderia expressar livremente a sua atividade criativa e produtiva. Contudo, considerando a defesa pedagógica realizada atualmente, com o aporte das filosofias da "diferença", e pela "valorização das múltiplas culturas", é preciso pontuar a divergência entre a diferença defendida por nós e a diferença defendida pelo ideário pós-moderno.

Ao defendermos a permanência das diferenças, nos referimos à diversidade das relações sociais que os indivíduos nutrem em sua experiência de vida, contudo, não desmerecemos ou desconsideramos as particularidades, as relações que os organismos biológicos mantém com o espaço em que vivem (LEFEBVRE, 2014c). Não podemos compreender o ser humano simplesmente por suas diferenças sociais, evitando as particularidades do gênero humano em relação às suas necessidades sociometabólicas. Caso o façamos, cairíamos em uma perspectiva fragmentária e dogmática, que nega qualquer tipo de compreensão totalizante do ser humano, contradizendo e eliminando toda a análise que realizamos até este momento.

O ideário pós-moderno apoia-se essencialmente nas diferenças, desprezando as particularidades e as relações criativas e produtivas do ser humano com os espaços naturais, tendo como resultado uma homogeneização que atua negativamente: ao invés de propagar o homogêneo por meio do nivelamento social e cultural, a homogeneidade é propagada por meio do igual isolamento e individualização dos grupos sociais; a diferença torna-se fundamento para a fragmentação das totalidades que constituem o ser humano, não tendo atuação alguma para o resgate do humano total. Daí considerarmos que, mesmo sem uma afirmação categórica, tais perspectivas atuam conjuntamente com as necessidades reprodutivas da sociedade capitalista, dificultando a organização da sociedade, propagando uma homogeneidade negativa e acentuando o individualismo9. A defesa das diferenças entre a nossa perspectiva e a perspectiva pósmoderna é radicalmente distinta.

De qualquer forma, como mencionamos, ao prezar pela transformação do espaço abstrato capitalista em um espaço diferencial, é necessário que estas transformações partam do e incidam no interior da vida cotidiana, é preciso que suas relações com o espaço social sejam transformadas. Mas como a vida cotidiana se relaciona com o espaço social? Para esclarecer esta questão, utilizaremos uma tríade conceitual proposta por Lefebvre (1991): a prática espacial, as representações do espaço e os espaços de representação.

A prática espacial se refere à dimensão percebida do espaço social, é por meio dela que a vida cotidiana flui, onde cada membro atuará diretamente para a produção e reprodução do espaço social no 
qual vive, garantindo a sua coesão e secretando as suas condições de produção; em suma, nos referimos aqui à prática social, mas relacionada à concreticidade do espaço social. As representações do espaço remetem à dimensão concebida do espaço social, aqui é onde caracterizamos os esforços daqueles que se dedicam à compreensão do espaço e para a produção do conhecimento científico, filosófico e, em alguns casos, artísticos. Os espaços de representação são aqueles vividos pelos usuários do espaço, onde a imediaticidade prevalece e, ao invés da análise crítica, há um privilégio das análises empírico-descritivas do espaço social. Cada indivíduo, no decorrer de sua vida cotidiana, passará necessariamente de uma para outra destas dimensões. Cada espaço social produzido e reproduzido por um determinado modo de produção, privilegiará mais uma destas dimensões do que as outras.

É importante compreender que o indivíduo, em sua vida cotidiana, perceberá o espaço social de uma determinada maneira, do ponto de vista de sua atividade produtiva ou de sua participação na reprodução da sociedade capitalista; este mesmo indivíduo viverá neste espaço social e depreenderá deste análises imediatistas da realidade em que vive, que apenas poderão ser desenvolvidas quando tiver contato com as concepções vigentes do espaço social, pois são estas que atuam diretamente na elaboração de estratégias para a reprodução das relações de produção. Defendemos, portanto, uma concepção de educação que englobe estas três dimensões das relações entre a vida cotidiana e o espaço social.

A educação escolar na sociedade capitalista, mais especificamente a educação voltada para as massas populares, privilegia principalmente o espaço vivido - como é realizado pelo multiculturalismo e pelas propostas pós-modernas - e o espaço percebido - como podemos perceber pela influência ainda perturbadora das pedagogias tecnicistas -, deixando de lado ou oferecendo apenas arremedos do espaço concebido, da apropriação e do domínio dos conhecimentos utilizados para a manutenção do espaço abstrato.

Defendemos que a valorização pontual do espaço vivido ou do espaço percebido, em detrimento de uma valorização da unidade entre estas dimensões, são na verdade duas faces de uma mesma necessidade formativa da sociedade capitalista: o afastamento da população da apropriação do conhecimento elaborado e sistematizado ao longo da história da humanidade. Este afastamento não é casual, não é acidental, ele é propagado ativamente no interior da educação escolar pelo fomento às perspectivas pedagógicas reducionistas e fragmentárias, que culminam, de maneira geral, em perspectivas negacionistas da realidade.

\section{Negação da realidade: a educação escolar e o conhecimento estranhado}

Oh, quão curto é o dizer, e traiçoeiro, / para o conceito! [...] (ALIGHIERI, 2019b, p. $233,121-122$

Nunca é demais reafirmarmos: o Estado capitalista atua direta e indiretamente na propagação, no interior da educação escolar pública, de um processo formativo fragmentário, insuficiente para que a população tenha acesso às concepções do espaço social utilizadas para a reprodução da sociedade capitalista. Atua diretamente por mecanismos já há muito conhecidos e debatidos, como o esvaziamento 
de conteúdos, o desmerecimento do trabalho docente, a falta de condições físicas e estruturais para as instituições escolares, dentre outros. Atua indiretamente ao absorver perspectivas pedagógicas fragmentárias em seus documentos oficiais, dissimuladas por meio de clichês como a "formação crítica", o "aprender a aprender", a "educação preparatória para o mundo do trabalho", a "formação do sujeito multicultural", o "respeito às diferenças", que permitem a adaptação confortável das mediações de segunda ordem da sociedade capitalista às mudanças impostas pelo desenvolvimento social e cultural.

Se almejamos uma educação que visa a formação humana total, não podemos prescindir de defender, no interior da educação escolar, a prevalência da transmissão dos conhecimentos elaborados e sistematizados ao longo da história da humanidade, sejam eles científicos, filosóficos ou artísticos, pois estes é que proverão os alunos com ferramentas teóricas e práticas para perceberem, viverem e terem acesso às concepções do espaço social, possibilitando assim a transformação da sociedade partindo de sua atividade cotidiana ${ }^{10}$

A negação do conhecimento objetivo, justificada por uma suposta crise da modernidade que colocou em xeque toda a racionalidade, uma das características marcantes das pedagogias das diferenças, das pedagogias multiculturais e das pedagogias pós-modernas - dentre várias propostas pedagógicas com as mesmas influências e que insistem em se subdividir infinitamente -, é uma postura que não apenas impossibilita a transformação social mas que também alimenta a reprodução do mesmo estado atual de coisas em que nos encontramos atualmente. Afirmar que há uma crise do conhecimento objetivo, da racionalidade, sendo que estes ainda atuam diretamente como forças produtivas (MARX, 1978) ou como meios de produção (SAVIANI, 2011b) para garantir a sobrevivência da sociedade capitalista, é de uma inocência indescritível, além de redundar em resultados catastróficos para a formação humana.

Ao defendermos a disseminação dos conhecimentos elaborados na educação escolar, deslocando o lugar privilegiado dado aos conhecimentos de senso comum pelas perspectivas pedagógicas já mencionadas, não estamos assumindo uma postura absolutista do conhecer. Os conhecimentos de senso comum são elaborados de maneira distinta que os conhecimentos aqui denominados elaborados, constituídos pela sociedade ao longo de sua história e utilizados como forças produtivas; sua formulação é também distinta daquela que o materialismo dialético preconiza, pois são embasados, de maneira geral, em observações empíricas da realidade, não submetidos a uma crítica rigorosa e transmitidos sem grande preocupação com o quão verdadeiramente representam a realidade concreta. O conhecimento produzido nunca será uma representação estritamente fiel e estática daquilo que buscamos apreender no pensamento, pois a própria realidade é dinâmica, contudo, se não possuirmos um critério do que seria o verdadeiro, de onde o conhecimento produzido deva se aproximar e para onde devemos direcioná-lo, nos tornamos reféns do relativismo, onde tudo pode ser considerado válido.

Os saberes de senso comum são momentos necessários para que consigamos alçar aos conhecimentos científicos, artísticos e filosóficos, se considerarmos todo o caminho da produção de um determinado conhecimento ou se considerarmos a apropriação do conhecimento já produzido no interior da educação escolar. Mas eles não podem ser considerados o fim do processo educativo. O desprezo pelos conceitos e categorias do conhecimento culmina no desprezo da objetividade da realidade, como se esta 
fosse inapreensível, plenamente inalcançável: se assim o fosse, qual seria o sentido de produzir conhecimento ou de se apropriar do conhecimento produzido? Tal postura no interior da educação escolar não faz nada mais do que propagar a desumanização e a fragmentação humana, utilizando como justificativa a beleza poética de valorizar as múltiplas culturas da humanidade e a subjetividade dos indivíduos que a compõem, de modo que

[...] um filosofar natural que se julga bom demais para o conceito, e devido à falta de conceito se tem em conta de um pensar intuitivo e poético, lança no mercado combinações caprichosas de uma força de imaginação somente desorganizada por meio do pensamento - imagens que não são carne nem peixe; que nem são poesia nem filosofia (HEGEL, 2014, p. 64, \$68).

Identificamos na educação escolar capitalista uma intencionalidade formativa clara de dela afastar quaisquer possibilidades para a apreensão da realidade, alimentando-a com fragmentos de conhecimento, quando presentes, ou com a transmissão de saberes de senso comum, cultural e regionalmente localizados, que não possuem a sistematicidade dos conhecimentos elaborados, que não participam ativamente da sociedade enquanto forças produtivas e, portanto, são inofensivos ao modo de produção capitalista ou, se nele atuam, é tão somente como novos meios para o avanço das intencionalidades mercadológicas e alienantes da autovalorização do capital, um meio para a expansão do consumo. Para definirmos o modo pelo qual o afastamento de ferramentas teóricas e práticas para a apreensão da realidade em relação à formação humana é incentivada pelo Estado capitalista, assumimos que a educação escolar pendula entre a produção de um estado social ora neurótico, ora psicótico. Tomamos de empréstimo estes termos de Freud (2011b), embora, para assim procedermos, se faz necessária a exposição de algumas precauções em relação à teoria psicanalítica.

Freud (2011a, p. 120) considera como constituintes do edifício teórico da psicanálise as "[...] teorias da resistência e da repressão, do inconsciente, da significação etiológica da vida sexual e da importância das vivências infantis". Consideramos que o inconsciente, junto das teorias da resistência e da repressão que dele derivam, constitui meramente um aparato ideológico, uma miragem fetichizada na qual os psicanalistas depositam tudo aquilo que ainda não conseguem entender sobre os processos do pensamento, incluindo "[...] the preconditions of consciousness in the nervous system or brain; action and language; what is remembered and what is forgotten; and the body and its own history" (LEFEBVRE, 1991, p. 208). Quanto à significação etiológica da vida sexual e de sua importância nas vivências infantis, encontramos o quadro teórico do complexo de Édipo, que aparentemente poderia ser encontrado em todos os fenômenos sociais que desejarmos analisar, possuindo supostamente uma grande força teóricoexplicativa. Contudo, consideramos que esta é mais uma perspectiva reducionista do ser humano, nascida do interior da prática psicanalítica de Freud, ao qual ele tenta moldar a realidade ao que observou dentro de seu consultório, resultando assim em uma interpretação mecanicista da realidade social (LEFEBVRE, 1991). Dizemos isso para demarcar que, apesar de utilizarmos estes conceitos de Freud, o fazemos deslocando-os de um arcabouço teórico do qual não podemos concordar.

Contudo, a definição que Freud utiliza para as neuroses e para as psicoses tem como fundamento as relações de proximidade do indivíduo com a realidade em que vive, e é isso que nos 
interessa. Para Freud (2011b) a psicose e a neurose podem ser compreendidas a partir de seu desenvolvimento em dois estágios, sendo que o primeiro em ambos os casos é caracterizado pelo distancimento do Eu da realidade em que vive, e ambos resultam em mecanismos de fuga da realidade. Para a psicose esta negação do real é remediada pela criação de uma nova realidade que não confronta a realidade anteriormente negada, mas a remodela no pensamento. Já para a neurose, a realidade negada é também sumamente evitada, o Eu tende a fugir da realidade.

Compreendemos que a educação aos moldes capitalistas atua diretamente na promoção de uma formação fragmentária, que fomenta a promoção deste primeiro estágio identificado por Freud: a negação da realidade. O que acontecerá depois, se o indivíduo irá negar a realidade a ponto de evitá-la ou irá produzir uma realidade abstrata remodelada na qual poderá conviver pacificamente, é indiferente, pois em ambos os casos o distanciamento da realidade é alcançado e as possibilidades de transformação social são eliminadas.

Quanto ao estado neurótico, é perceptível o negacionismo dos conhecimentos científicos presente nas esferas reacionárias da sociedade, onde o descrédito das investigações tornou-se comum e afirmações precárias e primitivas, aparentemente há muito deixadas no passado, começam a reemergir. Quanto ao estado psicótico, identificamos as propostas de formação que negam a objetividade do conhecimento produzido e voltam os objetivos da educação escolar para fragmentos culturais da realidade: são criadas assim realidades próprias nas quais os grupos sociais podem viver e conviver, não aceitando críticas vindas de fora, tampouco reconhecendo quaisquer ligações totalizantes entre o seu e outros grupos sociais.

A negação dos conhecimentos científicos, filosóficos e artísticos na educação escolar, em detrimento dos saberes de senso comum culturalmente localizados possui, também, uma estreita ligação com o próprio processo de ensino e de aprendizagem. Para isso, precisamos nos atentar para a diferenciação, no interior da teoria do campo semântico proposta por Lefebvre (2014b), entre sinais, símbolos e signos. A compreensão sobre os sinais e sua funcionalidade emerge com grande força a partir das teorias de Pavlov e do desenvolvimento teórico do behaviorismo, que indicaram a existência de fatores de condicionamento para a aprendizagem.

No campo educacional, as experiências de Skinner (1975) com as máquinas de ensinar propiciam um excelente exemplo de como os sinais podem e são aplicados na educação escolar atual; na vida cotidiana, ao pensarmos nos sinais de trânsito, temos outro grande exemplo de um sistema de sinais por excelência. Aquilo que emitirá um dado sinal pode ser qualquer coisa, desde que o processo de significação coincida com esta coisa, e o condicionamento propagado pelo sinal seja apropriado pelo indivíduo que o recebe sem um esforço consciente, de maneira direta, objetiva e estritamente racional, tal como uma máquina qualquer recebe um determinado comando.

Os símbolos, por sua vez, atuam de maneira contrária aos sinais, pois não podem ser esgotados pelo pensamento humano, agindo diretamente nas emoções e sensações das pessoas. Eles possuem um caráter mágico, com a capacidade de unir dois indivíduos aparentemente diferentes, ao mesmo tempo em que são razoavelmente imutáveis e inatacáveis, pois se distanciam da racionalidade objetiva. $\mathrm{O}$ sinal da Germinal: Marxismo e Educação em Debate, Salvador, v. 13, n. 3, p. 238-258, dez. 2021. ISSN: 2175-5604 253 
cruz realizado pelos católicos é um bom exemplo do poder cultural de um símbolo, apesar de ser denominado "sinal” (LEFEBVRE, 2014b). Já os signos possuem como elemento prototípico a palavra, que culmina na elaboração, gradualmente mais complexa, da linguagem. A linguagem não é nem fechada e nem aberta: ao mesmo tempo em que deve ser fechada, ser submetida a certas regras e normas para que possa ser transmitida e compreendida, deve também ser aberta, permitindo a emergência do novo. Ela possui um caráter abstrato e, quando atua em conjunto com o pensamento, possibilita a emersão do pensamento em conceitos, a forma mais complexa do pensamento humano (VIGOTSKI, 2009).

$\mathrm{Na}$ vida cotidiana, todos temos contato com sinais, símbolos e signos. Mas devemos nos atentar para o fato de que, em dados momentos históricos, estes três elementos do campo semântico podem ser deslocados de um para o outro, de modo que, por exemplo, um símbolo se torne um signo, e vice-versa. Quando crianças, nos processos inicias do desenvolvimento do pensamento, a linguagem é baseada principalmente em sinais, em estímulos que são recebidos e respondidos mecanicamente; posteriormente, com o contato com a cultura, a criança passa a se apropriar dos símbolos culturais; com a sua entrada na educação escolar, com a apropriação dos signos, da linguagem racionalizada e dos conceitos científicos, filosóficos e artísticos, após sucessivos processos de transformação de suas estruturas do pensamento, o indivíduo alcança a formação do pensamento em conceitos, o que o possibilita pensar abstratamente e objetivar este pensamento, realizando as mais complexas atividades humanas coerentes com o seu tempo histórico, o que só é possível ao dominar os signos.

O que ocorre na educação escolar propagada pela sociedade capitalista é o deslocamento entre os constituintes do campo semântico: ao invés de prezar por uma educação fundamentada na apropriação e objetivação de signos, da linguagem em sua forma mais elaborada e intimamente relacionada ao pensamento - o pensamento em conceitos -, os conhecimentos escolares tomam a forma de sinais, que são interpretados e assimilados mecanicamente pelos alunos, o que é característico das pedagogias tecnicistas.

Os conhecimentos escolares sofrem também deslocamento para formas simbólicas, assumindo um caráter mágico, dogmático e culturalmente localizado, que impossibilita a apropriação e a análise crítica, o que é característico das pedagogias pós-modernas. O resultado destes deslocamentos, para além da promoção de estados sociais neuróticos ou psicóticos, é a incapacidade, por um lado, da análise da realidade, que exige o estabelecimento de relacionamentos entre fenômenos, o que é impossibilitado por apropriações mecânicas que focam na pontualidade, na superficialidade fenomênica, não reconhecendo suas múltiplas determinações; ou então a incapacidade de realizar análises críticas e radicais dos fenômenos da realidade, que consigam ultrapassar os limites de sua própria circunscrição cultural e alçar à uma análise totalizante. Em ambos os casos a eliminação da possibilidade de transformação da sociedade é cultivada; em ambos os casos a reprodução das relações de produção capitalistas segue ininterruptamente.

O pensamento de um adulto não funciona somente pelo pensamento em conceitos, podendo variar para formas menos complexas do funcionamento cognitivo (VIGOTSKI, 2009), e isto é normal. O que não pode ser considerado normal, tampouco aceitável, é uma educação escolar que promove, como demonstramos, uma formação humana completamente fragmentária e insuficiente para a apropriação dos Germinal: Marxismo e Educação em Debate, Salvador, v. 13, n. 3, p. 238-258, dez. 2021. ISSN: 2175-5604 254 
conhecimentos elaborados - seja pela ausência de fomento para o desenvolvimento psicológico, seja pela negação da oferta de oportunidades de acesso a eles -, e que atua diretamente em uma formação humana que abandona e que nega qualquer vestígio de objetividade da realidade, em prol de interpretações carentes de coesão e de coerência, de análises sociais delimitadas no interior de um determinado grupo social e cultural, reduzindo o humano total, dirimindo as possibilidades de que o desenvolvimento do pensamento dos indivíduos alcem ao pensamento em conceitos, consequentemente, dirimindo as possibilidades de compreensão da própria situação de miséria em que a maior parte da população na sociedade capitalista é arremessada. O resultado de todo este processo formativo não pode ser outro que não o pleno estranhamento dos indivíduos em relação aos conhecimentos elaborados e à educação escolar.

\section{Considerações finais}

Vou a Marselha algumas vezes a pé devorar laranjas ordinárias, de um vintém, quase podres, [...] e seu bolor azulado ou esverdeado brilha a meus olhos como diamantes; vejo nele flores, não tenho impressão nenhuma de seu cheiro corrompido e acho-lhe um sabor irritante, um calor vinhoso, um delicioso gosto. [...] Essas horríveis laranjas são os meus amores (BALZAC, 2012, p. 411)

Iniciamos este texto afirmando nossa posição ao almejarmos uma formação humana total; afirmamos que o Estado capitalista atua conjuntamente às personificações do capital e suas outras mediações de segunda ordem para a garantia da reprodução de suas relações de produção; intentamos demonstrar como, no ambiente escolar, a promoção de pedagogias de teor tecnicista e relativista são somadas às intencionalidades de uma formação desumana, fragmentária e alienante; identificamos a vida cotidiana como esfera privilegiada para a partida da transformação da sociedade, pois é dela que todas as atividades humanas, sejam elas consideradas simples ou complexas, emergem; finalizamos demonstrando como, ao promover a negação da realidade e instituir estados sociais neuróticos e psicóticos, a educação escolar capitalista promove a incapacidade de um enfrentamento efetivo, cingindo qualquer possibilidade conjunta de ataque às estruturas da sociedade capitalista.

Asseveramos que qualquer proposta de educação escolar que relativize a importância da apropriação dos conhecimentos sistematizados e elaborados ao longo da história da humanidade não passa de uma proposta de formação desumanizante, muito distante da formação humana total que aqui preconizamos, que possui como objetivo último a transformação da sociedade capitalista. Não negamos, de maneira alguma, a importância da linguagem para a educação escolar e a importância da preservação dos diversos grupos culturais existentes no mundo, contudo, não podemos admitir que apenas um ou outro sejam pinçados como determinantes absolutos da experiência humana.

Assim como na epígrafe que utilizamos nestas considerações finais, tais teóricos que relativizam ou ignoram a objetividade do conhecimento e seu lugar na educação escolar vislumbram os saberes de senso comum, a cultura particularizada e o sujeito da linguagem como seus amores, como saborosos objetivos dos quais devem desfrutar, e de fato o são. Contudo, se tomarmos a linguagem ou a cultura como absolutas para a concepção de formação humana que defendemos, desfrutaremos destes saborosos 
frutos sem notarmos o que possivelmente há de negativo em seu interior, nos alimentaremos de algo podre, engoliremos à seco e sem perceber a manutenção do modo de produção capitalista.

As elaborações até aqui realizadas podem ser consideradas hipóteses na medida em que, reconhecemos, há ainda maiores aprofundamentos a serem realizados, que não apenas excedem o espaço de um artigo, mas também excedem o recorte temporal de nossa capacidade investigativa. Destacamos, por fim, duas possibilidades de aprofundamento que, consideramos, devem ser abordadas para a constituição sólida da elaboração que aqui realizamos: é possível e desejável a realização de investigações para a observância e análise da formação do pensamento em conceitos em indivíduos egressos da educação escolar, para a possível constatação da regressão da formação do pensamento que julgamos ocorrer, bem como a investigação minuciosa de análises já realizadas com este intuito; o próprio arcabouço teórico que aqui utilizamos deverá ser inegavelmente aprofundado, com a intenção de esmiuçar, cada vez mais, os mecanismos utilizados pela educação escolar capitalista e de seus congêneres, para produzir a imobilidade dos indivíduos e a mobilidade do modo de produção dominante.

\section{Agradecimentos}

Os autores agradecem ao Grupo de Estudos e Pesquisas sobre Trabalho, Política e Educação Escolar (UFSCar), pelas discussões e pela reflexão coletiva proporcionada, e à Victor Ribeiro da Silva, pela leitura preliminar do texto e pelo auxílio com as traduções.

\section{Referências:}

ALIGHIERI, D. A divina comédia: inferno. 5. ed. São Paulo: Editora 34, 2019a.

ALIGHIERI, D. A divina comédia: paraíso. 5. ed. São Paulo: Editora 34, 2019b.

BALZAC, H. Memórias de duas jovens esposas. In: BALZAC, H. A comédia humana: estudos de costumes: cenas da vida privada; v. 1. 3. ed. São Paulo: Globo, 2012. pp. 266-515.

DUARTE, N. Vigotski e o "aprender a aprender": crítica às apropriações neoliberais e pós-modernas da teoria vigotskiana. 3. ed. Campinas: Autores Associados, 2004.

FREIRE, P. A importância do ato de ler: em três artigos que se completam. 23. ed. São Paulo: Autores Associados; Cortez, 1989.

FREUD, S. "Autobiografia" (1925). In: FREUD, S. Obras completas, volume 16: O Eu e o Id, "Autobiografia" e outros textos (1923-1925). São Paulo: Companhia das Letras, 2011a. pp. 75-167.

FREUD, S. A perda da realidade na neurose e na psicose (1924). In: FREUD, S. Obras completas, volume 16: O Eu e o Id, “Autobiografia” e outros textos (1923-1925). São Paulo: Companhia das Letras, 2011b. pp. 214-221.

HARVEY, D. Condição pós-moderna: uma pesquisa sobre as origens da mudança cultural. 17. ed. São Paulo: Edições Loyola, 2008.

HEGEL, G. W. F. Fenomenologia do espírito. 9. ed. Petrópolis: Vozes; Bragança Paulista: Editora Universitária São Francisco, 2014. 
LEFEBVRE, H. Critique of everyday life, volume I: introduction. In: LEFEBVRE, H. Critique of everyday life: the one-volume edition. London; New York: Verso, 2014a. pp. 1-272; 845-863.

LEFEBVRE, H. Critique of everyday life, volume II: foundations for a sociology of the everyday. In: LEFEBVRE, H. Critique of everyday life: the one-volume edition. London; New York: Verso, 2014b. pp. 273-652; 864-878.

LEFEBVRE, H. Critique of everyday life, volume III: from modernity to modernism (towards a metaphilosophy of daily life). In: LEFEBVRE, H. Critique of everyday life: the one-volume edition. London; New York: Verso, 2014c. pp. 653-842; 879-886.

LEFEBVRE, H. The production of space. Oxford: Blackwell Publishing, 1991.

MARX, K. Grundrisse: manuscritos econômicos de 1857-1858: esboços da crítica da economia política. São Paulo: Boitempo; Rio de Janeiro: Ed. UFRJ, 2011.

MARX, K. Manuscritos econômico-filosóficos. São Paulo: Boitempo, 2010.

MARX, K. O capital: livro I: capítulo VI (inédito). São Paulo: Livraria Editora Ciências Humanas LTDA., 1978.

MÉSZÁROS, I. Para além do capital: rumo a uma teoria da transição. São Paulo: Boitempo, 2011.

PISTRAK, M. Fundamentos da escola do trabalho. São Paulo: Expressão Popular, 2000.

SAVIANI, D. Antecedentes, origem e desenvolvimento da pedagogia histórico-crítica. In: MARSIGLIA, A. C. G. (Org.). Pedagogia histórico-crítica: 30 anos. Campinas: Autores Associados, 2011a. pp. $197-$ 225.

SAVIANI, D. Pedagogia histórico-crítica: primeiras aproximações. 11. ed. Campinas: Autores Associados, 2011b.

SILVA, T. T. Documentos de identidade: uma introdução às teorias do currículo. 3. ed. Belo Horizonte: Autêntica, 2010.

SKINNER, B. F. Tecnologia do ensino. São Paulo: Editora Pedagógica e Universitária Ltda.; Editora da Universidade de São Paulo, 1975.

VIGOTSKI, L. S. A construção do pensamento e da linguagem. 2. ed. São Paulo: Editora WMF Martins Fontes, 2009.

\footnotetext{
Notas:

${ }^{1}$ Doutorando em Educação pela Universidade Federal de São Carlos (UFSCar). Mestre em Educação para a Ciência pela Universidade Estadual Paulista "Júlio de Mesquita Filho" (UNESP). Integrante do Grupo de Estudos e Pesquisas sobre Trabalho, Política e Educação Escolar. Professor de Educação Básica no estado de São Paulo. Currículo Lattes: http://lattes.cnpq.br/4028983402211189 . Orcid: https://orcid.org/0000-0001-6751-2084 . E-mail: paulohvasc@gmail.com . 2 Pós-Doutora pelo Instituto de Educação da Universidade de Lisboa (IE-ULISBOA). Pós-Doutora em Ambiente e Sociedade pela Universidade Estadual de Goiás (PPGAS/UEG). Doutora em Educação pela Universidade Estadual de Campinas (UNICAMP). Coordenadora do Grupo de Estudos e Pesquisas sobre Trabalho, Política e Educação Escolar. Professora do Programa de Pós-Graduação em Educação da Universidade Federal de São Carlos (UFSCar). Currículo Lattes: http://lattes.cnpq.br/1095065753077001 . Orcid: https://orcid.org/0000-0003-3130-9433 . E-mail: cbezerra@ufscar.br .

3 "No horizonte, portanto, no mais longínquo limite do possível, se trata de produzir o espaço da espécie humana - a obra coletiva (genérica) da espécie - no modelo do que se costumava chamar de "arte". A criação (ou produção) de um espaço planetário como alicerce social de uma vida cotidiana transformada, aberta a uma miríade de possibilidades - tal é o alvorecer que começa a despontar no horizonte distante". As traduções das citações diretas de Lefebvre (1991) neste texto são traduções de traduções (do francês para o inglês e do inglês para o português) realizadas por nós. Por este motivo elas possuem apenas caráter informativo ao leitor que não domina a língua inglesa.

4 A proposição de uma escola do trabalho, como defendida por Pistrak (2000), é justificada pela carência científico-tecnológica de sua localização espaço-temporal, bem como pela necessidade de que aquela sociedade revolucionária tivesse meios materiais para subsistência e para a proteção contra os constantes ataques e avanços das nações capitalistas que a rodeavam. Apesar de compreensível em seu contexto, não podemos assumir que o único direcionamento possível de uma formação para o trabalho é a emancipação da população: o período stalinista que acompanha temporalmente a obra de Pistrak foi também marcado pela Germinal: Marxismo e Educação em Debate, Salvador, v. 13, n. 3, p. 238-258, dez. 2021. ISSN: 2175-5604 257
} 
alienação do trabalho, mas ao invés do mais-trabalho ser apropriado pelas personificações do capital, era apropriado pelo poder estatal pós-capitalista. Atualmente, no Brasil, podemos observar esta influência no movimento por uma educação do campo, onde é buscada a fundamentação de um processo educativo localmente situado nas especificidades produtivas (e culturais) da população rural.

${ }^{5}$ Nos referimos mais especificamente à obra de Freire (1989), que identifica a análise e a interpretação de textos, em sua argumentação sobre a importância de aprender a ler, com a análise e a interpretação da realidade. Apesar das influências marxistas na obra de Freire, as perspectivas pedagógicas pós-modernas, com a centralização da linguagem e do discurso que defendem, se apropriam convenientemente de sua afirmação, levando adiante um posicionamento que já de início se mostrava problemático, pois trata a realidade de maneira reducionista, como um texto a ser lido.

6 “[...] nunca salvou o mundo e nunca irá salvá-lo" (tradução nossa).

7 “Capitalismo e neocapitalismo produziram o espaço abstrato, que inclui o 'mundo das mercadorias', sua 'lógica' e suas estratégias mundiais, bem como os poderes do dinheiro e do estado político. Este espaço é alicerçado em uma vasta rede de bancos, centros comerciais e pelas maiores entidades produtivas, bem como rodovias, aeroportos e redes de informação" (tradução nossa).

8 "Enquanto a vida cotidiana permanecer como uma serva do espaço abstrato, com suas restrições concretas; enquanto as únicas melhorias que ocorrerem forem melhorias técnicas pontuais (por exemplo, a frequência e a velocidade de transporte, ou amenidades relativamente melhores); enquanto, em suma, as únicas conexões entre espaços de trabalho, de lazer e de viver forem fornecidas por agências do poderio político e por mecanismos de controle - o projeto de uma 'mudança de vida' permanecerá sendo não mais do que uma palavra de ordem que será tomada ou abandonada de acordo com a ocasião" (tradução nossa).

9 Podemos situar dois autores, constantemente utilizados como referências para a discussão sobre as influências do pósmodernismo na área da educação, cada um deles adotando um posicionamento distinto: Silva (2010) analisa as teorias do currículo e enfatiza a necessidade de que elas adotem um fundamento pós-moderno, prezando ao máximo pelas "diferenças" e, inclusive, não vendo problema algum no abandono da categoria materialista dialética da totalidade; Duarte (2004) critica a base pósmoderna de alguns autores que tentam adotar a teoria psicológica em Vigotski, com foco na relativização dos conhecimentos e na defesa inerente ao capitalismo presente nestas investidas, o que contradiz as próprias bases marxistas em que Vigotski se funda para a fundamentação e elaboração de suas obras. Para uma perspectiva mais geral do pós-modernismo, com uma análise histórica desde suas origens até suas influências atuais, estas últimas elencadas brevemente brevemente neste texto, recomendamos a leitura de Harvey (2008)

10 Isto não significa, obviamente, que a educação escolar e a escola são as únicas origens das quais uma transformação da sociedade capitalistaseria originada, mas sim que elas constituem um dos principais meios, atualmente, para o acesso da massa populacional ao conhecimento sistematizado, daí a sua importância - específica - para o cumprimento desta condição, da apropriação de conhecimentos, para a transformação revolucionária. 